\title{
Anticancer Effect of an Electronically Coupled Oligoferrocene
}

Gina Zeh, ${ }^{\mathrm{a}}$ Philipp Haines, ${ }^{\mathrm{b}}$ Matthias E. Miehlich, ${ }^{\mathrm{c}}$ Torben Kienz, ${ }^{\mathrm{d}}$ Andreas Neidlinger, ${ }^{\mathrm{d}}$ Ralf P. Friedrich, ${ }^{\mathrm{e}}$ Hülya G. Özkan, ${ }^{\mathrm{a}}$ Christoph Alexiou, ${ }^{\mathrm{e}}$ Frank Hampel, ${ }^{\mathrm{a}}$ Dirk M. Guldi, ${ }^{\mathrm{b}}$ Karsten Meyer, ${ }^{\mathrm{c}}$ Jürgen Schatz, ${ }^{\mathrm{a}}$ Katja Heinze, ${ }^{\mathrm{d}}$ Andriy Mokhir ${ }^{*, \mathrm{a}}$

a Friedrich-Alexander University of Erlangen-Nuremberg (FAU), Department of Chemistry and Pharmacy, Organic Chemistry, Nikolaus-Fiebiger-Str. 10, 91058 Erlangen, Germany, Andriy.Mokhir@fau.de

b Friedrich-Alexander University of Erlangen-Nuremberg (FAU), Department of Chemistry and Pharmacy, Physical Chemistry, Egerlandstr. 3, 91058 Erlangen, Germany

c Friedrich-Alexander University of Erlangen-Nuremberg (FAU), Department of Chemistry and Pharmacy, Inorganic Chemistry, Egerlandstr. 1, 91058 Erlangen, Germany

d Johannes-Gutenberg University of Mainz, Department of Chemistry, Duesbergweg 10-14, 55128 Mainz

e Department of Otorhinolaryngology, Head and Neck Surgery, Section of Experimental Oncology and Nanomedicine (SEON), Else Kröner-Fresenius-Stiftung-Professorship, Universitätsklinikum Erlangen, Glückstraße 10a, 91054 Erlangen, Germany.

Content

\begin{tabular}{|c|c|}
\hline Details of crystal structures of monomer $\mathbf{6}$ and dimer $\mathbf{8}$ & S2-S3 \\
\hline Calibration plot used for determination of $\log \mathrm{P}$ values & S4 \\
\hline $\begin{array}{l}\text { Determination of stability of monomer } \mathbf{3} \text { and dimer } \mathbf{1 0} \text { in different } \\
\text { solutions }\end{array}$ & S5-S6 \\
\hline Mössbauer spectrum of tetramer $\mathbf{1 3}$ & S7 \\
\hline $\begin{array}{l}\text { Data on ROS production in BL- } 2 \text { cells in the presence of different } \\
\text { ferrocene derivatives }\end{array}$ & $\mathrm{S} 8$ \\
\hline
\end{tabular}


Table S1. Crystal data and refinement details for monomer 6.

\begin{tabular}{|c|c|c|c|}
\hline Empirical formula & $\mathrm{C}_{16} \mathrm{H}_{21} \mathrm{FeNO}_{2}$ & $\rho_{\text {calc }} \mathrm{g} / \mathrm{cm}^{3}$ & 1.391 \\
\hline Formula weight & 315.19 & $\mu / \mathrm{mm}^{-1}$ & 8.033 \\
\hline Temperature/K & $153.2(5)$ & $\mathrm{F}(000)$ & 1328.0 \\
\hline Crystal system & orthorhombic & Crystal size $/ \mathrm{mm}^{3}$ & $0.1 \times 0.07 \times 0.047$ \\
\hline Space group & Pbca & $2 \Theta$ range for data collection/ ${ }^{\circ}$ & 6.836 to 129.038 \\
\hline $\mathrm{a} / \AA$ & $11.4686(2)$ & Index ranges & $\begin{array}{l}-4 \leq \mathrm{h} \leq 12,-11 \leq \mathrm{k} \leq 11 \\
-29 \leq 1 \leq 21\end{array}$ \\
\hline $\mathrm{b} / \AA$ & $10.1506(3)$ & Reflections collected & 7953 \\
\hline $\mathrm{c} / \AA$ & $25.8642(6)$ & Independent reflections & $\begin{array}{l}2468\left[R_{\text {int }}=0.0442, R_{\text {sigma }}\right. \\
=0.0420]\end{array}$ \\
\hline$\alpha /^{\circ}$ & 90 & Data/restraints/parameters & $2468 / 15 / 197$ \\
\hline$\beta /{ }^{\circ}$ & 90 & Goodness-of-fit on $\mathrm{F}^{2}$ & 1.319 \\
\hline$\gamma /{ }^{\circ}$ & 90 & Final $\mathrm{R}$ indexes $[\mathrm{I}>=2 \sigma(\mathrm{I})]$ & $\begin{array}{l}\mathrm{R}_{1}=0.0640, \mathrm{wR}_{2}= \\
0.1330\end{array}$ \\
\hline Volume $/ \AA^{3}$ & $3010.93(12)$ & Final $\mathrm{R}$ indexes [all data] & $\begin{array}{l}\mathrm{R}_{1}=0.0791, \mathrm{wR}_{2}= \\
0.1378\end{array}$ \\
\hline $\mathrm{Z}$ & 8 & Largest diff. peak/hole / e $\AA^{-3}$ & $0.36 /-0.40$ \\
\hline
\end{tabular}


Table S2. Crystal data and refinement details for dimer $\mathbf{8}$.

\begin{tabular}{|l|l||l|l|}
\hline Empirical formula & $\mathrm{C}_{25} \mathrm{H}_{26} \mathrm{Fe}_{2} \mathrm{~N}_{2} \mathrm{O}_{4}$ & $\rho_{\text {calc }} / \mathrm{cm}^{3}$ & 1.527 \\
\hline Formula weight & 530.18 & $\mu / \mathrm{mm}^{-1}$ & 10.377 \\
\hline Temperature/K & $153.05(10)$ & $\mathrm{F}(000)$ & 1096.0 \\
\hline Crystal system & monoclinic & Crystal size $/ \mathrm{mm}^{3}$ & $0.559 \times 0.122 \times 0.089$ \\
\hline Space group & $\mathrm{C} 2 / \mathrm{c}$ & $2 \Theta$ range for data collection/ & \\
\hline $\mathrm{a} / \AA$ & $22.2047(8)$ & Index ranges & 9.436 to 129.044 \\
\hline $\mathrm{b} / \AA$ & $10.3393(3)$ & Reflections collected & $-25 \leq \mathrm{h} \leq 20,-12 \leq \mathrm{k} \leq 9,-6 \leq 1$ \\
& & & 3030 \\
\hline $\mathrm{c} / \AA$ & $10.0447(4)$ & Independent reflections & $1606\left[\mathrm{R}_{\text {int }}=0.0329, \mathrm{R}_{\text {sigma }}=\right.$ \\
\hline$\alpha /{ }^{\circ}$ & & & $0.0348]$ \\
\hline$\beta /{ }^{\circ}$ & 90 & Data/restraints/parameters & $1606 / 0 / 150$ \\
\hline$\gamma /{ }^{\circ}$ & $90.343(4)$ & Goodness-of-fit on $\mathrm{F}^{2}$ & 1.069 \\
\hline $\mathrm{Volume} / \AA^{3}$ & $2306.03(13)$ & Final R indexes [all data] & $\mathrm{R}_{1}=0.0432, \mathrm{wR}_{2}=0.1065$ \\
\hline $\mathrm{Z}$ & 4 & Largest diff. peak/hole $/ \mathrm{e} \AA^{-3}$ & $0.50 /-0.33$ \\
\hline
\end{tabular}




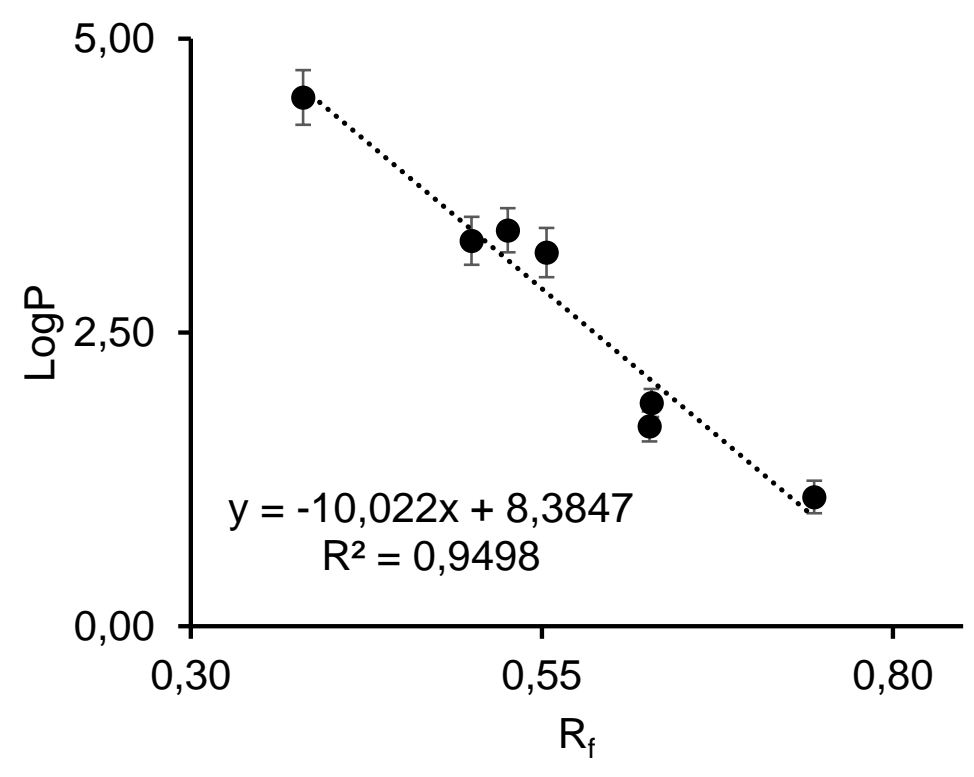

- References ......... Linear (References)

Figure S1. Calibration plot of $\log \mathrm{P}$ versus $\mathrm{R}_{\mathrm{f}}$ used for determination of $\log \mathrm{P}$ values of new ferrocene derivatives by using reverse phase thin layer chromatography (Table 1). A list of reference compounds used to prepare this calibration plot is provided in the experimental section of the main text of the paper. 


\section{Determination of stability of monomer 3 and dimer 10 in different aqueous solutions}

To study the hydrolytic stability of the compounds $\mathbf{3}$ and 10, thin layer chromatography (RP-TLC, Macherey Nagel, Germany, ALUGRAM RP-18 W/UV254, stationary layer thickness $0.150 \mathrm{~mm}$ ) was used. Acetonitril (AcCN) / aqueous 3-(N-morpholino)propanesulfonic acid buffer (MOPS, 0.1 M, pH 7.4, 1/1, v/v) was applied as a mobile phase (further eluent). Compounds $\mathbf{3}$ and $\mathbf{7}$ were dissolved in $\operatorname{AcCN}(2 \mathrm{mM})$. These solutions were mixed (1/1, v/v) with either phosphate buffered saline (PBS, 10 $\mathrm{mM} \mathrm{PO}_{4}{ }^{3-}$ and $150 \mathrm{mM} \mathrm{NaCl}, \mathrm{pH}$ 7.4) or PBS containing either glutathione (GSH, $5 \mathrm{mM}$ ) or sodium ascorbate (Asc, $1 \mathrm{mM}$ ) or hydrogen peroxide $\left(\mathrm{H}_{2} \mathrm{O}_{2}, 1 \mathrm{mM}\right)$ or pure culture media (RPMI 1640 medium containing 5\% FBS, $1 \%$ L-glutamine, and $1 \%$ penicillin/streptomycin). Compounds dissolved in pure AcCN were applied as a control. The mixtures were incubated at $22{ }^{\circ} \mathrm{C}$. They were spotted on TLC plates $(2.0 \mu \mathrm{L})$ at $15 \mathrm{~mm}$ distance from the edge of the plate in every $12 \mathrm{~h}$ during $48 \mathrm{~h}$ starting from the initial time point $0 \mathrm{~h}$. The solvent was allowed to migrate for $4.5 \mathrm{~cm}$. Finally, the spots were visualized by illumination with UV-lamp $(254 \mathrm{~nm})$ and further stained with aqueous $\mathrm{KMnO}_{4}$ solution.

In TLCs the order of the spots (Figures S2 and S3): 1. PBS; 2. PBS + GSH 5 mM; 3. PBS + Sodium Lascorbate $1 \mathrm{mM}$; 4. PBS $+\mathrm{H}_{2} \mathrm{O}_{2} 1 \mathrm{mM} ; 5.5 \%$ FBS containing RPMI medium; 6. AcCN
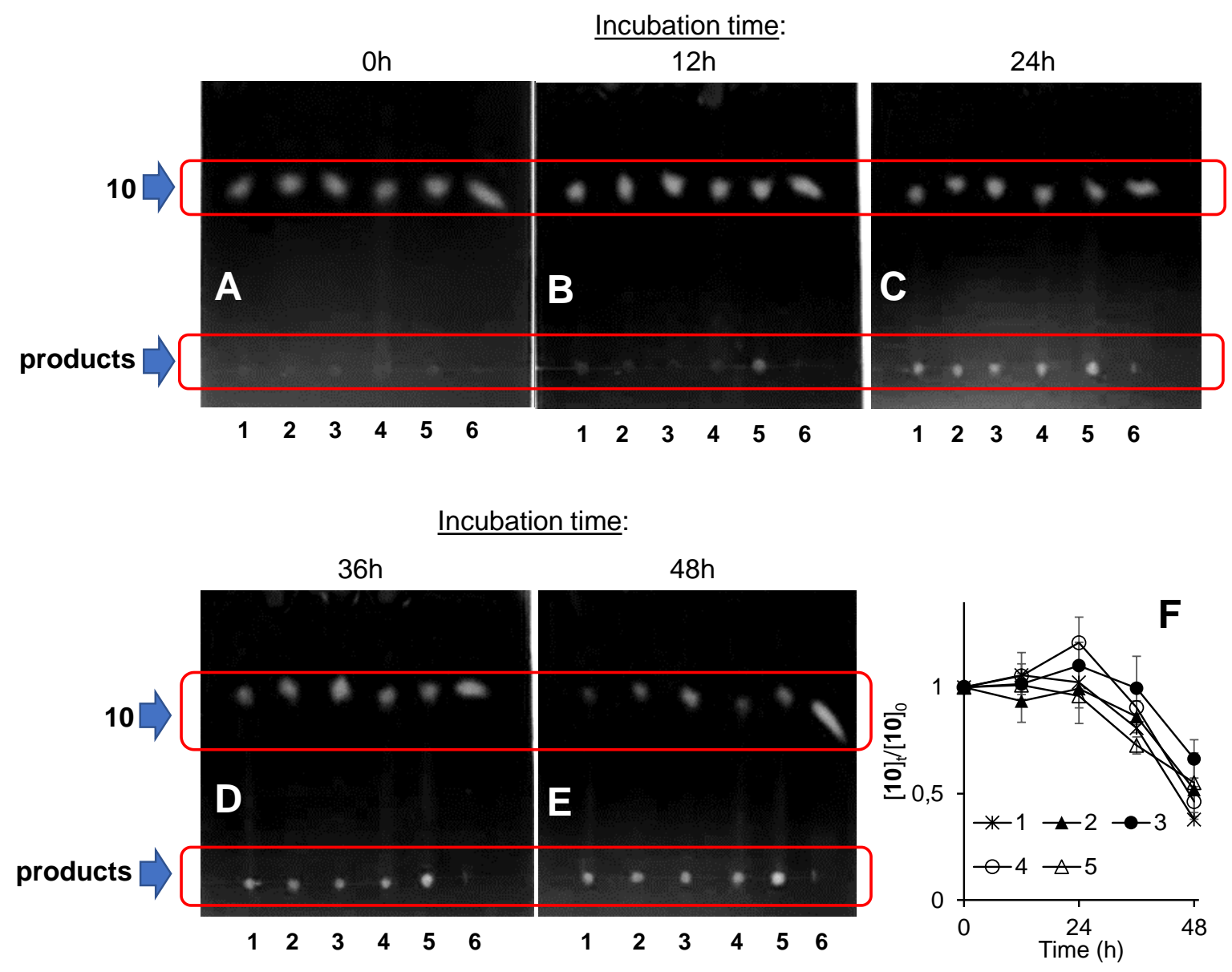

Figure S2. Analysis of stability of dimer 10 in different aqueous solutions 1-5 and control in AcCN (6): plots A-E. Detailed description of the content of these solutions is provided in the experimental description above. For this analysis thin layer chromatography was used. Times of incubation of the dimer in these solutions are indicated on the plot. Quantification of these data ([dimer 10 $]_{t} /[\text { dimer } \mathbf{1 0}]_{0}$ versus time) is shown in plot $\mathrm{F}$. 


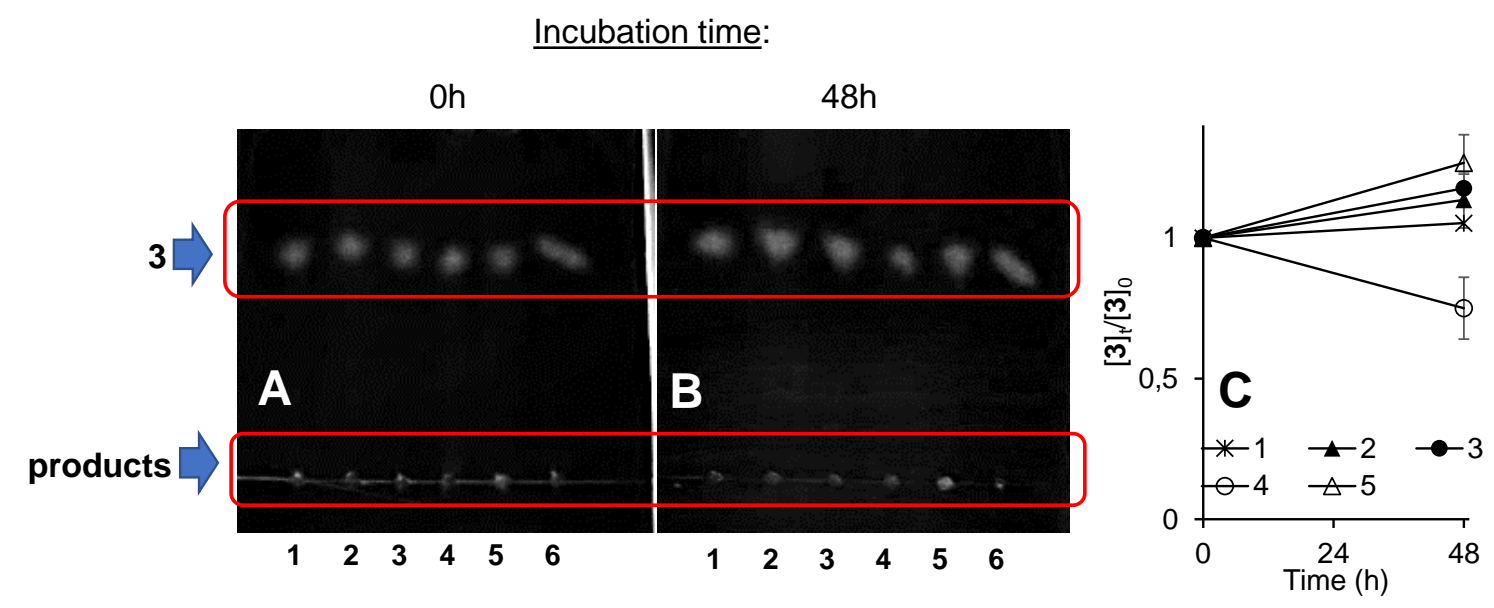

Figure S3. Analysis of stability of monomer 3 in different aqueous solutions 1-5 and control in AcCN (6): plots A, B. Detailed description of the content of these solutions is provided in the experimental description above. For this analysis thin layer chromatography was used. Times of incubation of the dimer in these solutions are indicated on the plot. Quantification of these data ([dimer 3] $/[\text { dimer 3 }]_{0}$ versus time) is shown in plot $\mathrm{C}$. 


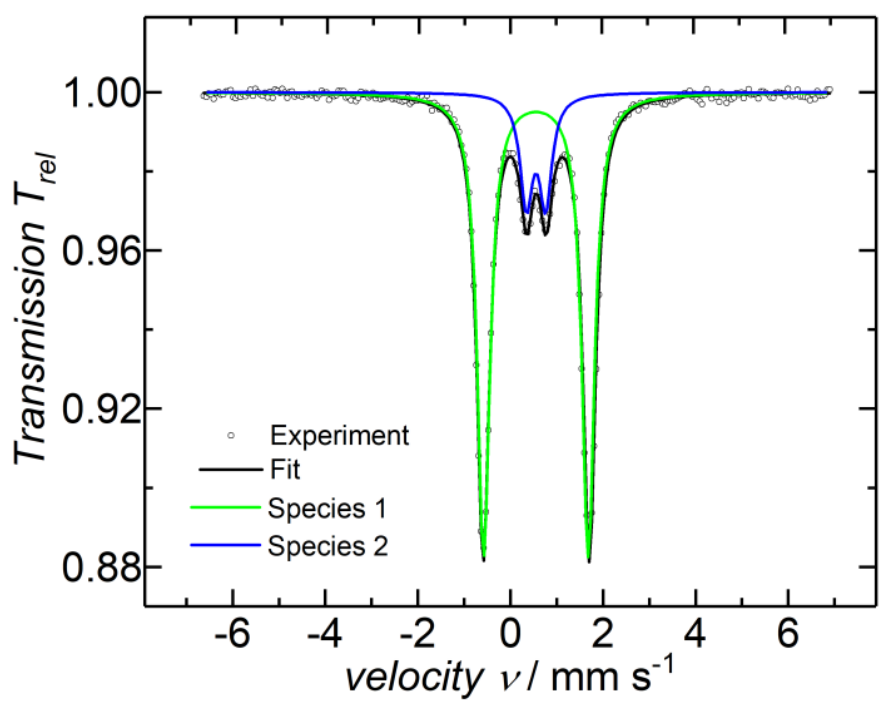

Figure S4. Mössbauer spectrum of solid sample of tetramer 13. Zero-field ${ }^{57} \mathrm{Fe}$ Mössbauer data were recorded on a WissEl spectrometer (MRG-500) at $77 \mathrm{~K}$ with alternating constant acceleration. ${ }^{57} \mathrm{Co} / \mathrm{Rh}$ was used as the radiation source. The minimum experimental line width was $0.21 \mathrm{~mm} \mathrm{~s}^{-1}$ (full width at half-height). The temperature of the samples was controlled by an MBBC-HE0106 MÖSSBAUER $\mathrm{He} / \mathrm{N}_{2}$ cryostat within an accuracy of $\pm 0.3 \mathrm{~K}$. Isomer shifts were determined relative to $\alpha$-iron at $298 \mathrm{~K}$.

Table S3. Parameters of Mössbauer spectrum of solid sample of tetramer $\mathbf{1 3 .}$

\begin{tabular}{|l|c|c|}
\hline & Species 1 & Species 2 \\
\hline Type & $81 \%$ & $19 \%$ \\
$\delta\left(\mathrm{mm} \mathrm{s}^{-1}\right)$ & doublet & doublet \\
$\Delta \mathbf{E}_{\mathbf{Q}}\left(\mathrm{mm} \mathrm{s}^{-1}\right)$ & $\mathbf{0 . 5 6}$ & $\mathbf{0 . 5 6}$ \\
$\Gamma_{\text {FWнм }}\left(\mathrm{mm} \mathrm{s}^{-1}\right)$ & $\mathbf{2 . 2 9}$ & $\mathbf{0 . 4 2}$ \\
\hline
\end{tabular}




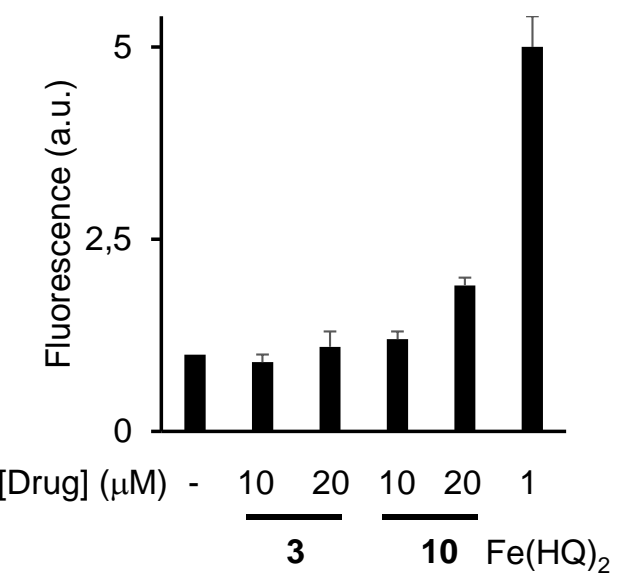

Figure S5. Oxidative stress induced in Burkitt's lymphoma BL-2 cells by their incubation with ferrocene derivatives $\mathbf{3}$ and $\mathbf{1 0}$ as well as positive control $\mathrm{Fe}(\mathrm{HQ})_{2}$. 